\title{
Wound healing of human embryonic stem cell-derived retinal pigment epithelial cells is affected by maturation stage
}

\author{
Amna E. Abu Khamidakh', Alejandra Rodriguez-Martinez², Kai Kaarniranta ${ }^{3,4}$, Anne Kallioniemi², \\ Heli Skottman ${ }^{2}$, Jari Hyttinen ${ }^{1}$ and Kati Juuti-Uusitalo ${ }^{2^{*}}$ (1)
}

\begin{abstract}
${ }^{*}$ Correspondence:
kati.juuti-uusitalo@staff.uta.fi

2 Faculty of Medical and Life

Sciences, BioMediTech,

University of Tampere, Arvo

Ylpön Katu 34, Tampere,

Finland

Full list of author information

is available at the end of the article
\end{abstract}

\begin{abstract}
Background: Wound healing of retinal pigment epithelium (RPE) is a complex process that may take place in common age-related macular degeneration eye disease. The purpose of this study was to evaluate whether wounding and wound healing has an effect on $\mathrm{Ca}^{2+}$ dynamics in human embryonic stem cell (hESC)-RPEs cultured different periods of time.

Methods: The 9-day-cultured or 28-day-cultured hESC-RPEs from two different cell lines were wounded and the dynamics of spontaneous and mechanically induced intracellular $\mathrm{Ca}^{2+}$ activity was measured with live-cell $\mathrm{Ca}^{2+}$ imaging either immediately or 7 days after wounding. The healing time and speed were analyzed with time-lapse bright field microscopy. The $\mathrm{Ca}^{2+}$ activity and healing speed were analysed with image analysis. In addition the extracellular matrix deposition was assessed with confocal microscopy.

Results: The $\mathrm{Ca}^{2+}$ dynamics in hESC-RPE monolayers differed depending on the culture time: 9-day-cultured cells had higher number of cells with spontaneous $\mathrm{Ca}^{2+}$ activity close to freshly wounded edge compared to control areas, whereas in 28-daycultured cells there was no difference in wounded and control areas. The 28-day-cultured, wounded and 7-day-healed hESC-RPEs produced wide-spreading intercellular $\mathrm{Ca}^{2+}$ waves upon mechanical stimulation, while in controls propagation was restricted. Most importantly, both wave spreading and spontaneous $\mathrm{Ca}^{2+}$ activity of cells within the healed area, as well as the cell morphology of 28-day-cultured, wounded and thereafter 7-day-healed areas resembled the 9-day-cultured hESC-RPES.
\end{abstract}

Conclusions: This acquired knowledge about $\mathrm{Ca}^{2+}$ dynamics of wounded hESC-RPE monolayers is important for understanding the dynamics of RPE wound healing, and could offer a reliable functionality test for RPE cells. The data presented in here suggests that assessment of $\mathrm{Ca}^{2+}$ dynamics analysed with image analysis could be used as a reliable non-invasive functionality test for RPE cells.

Keywords: Image analysis, hESC-RPE, RPE, Cell maturation, Wound healing, Spontaneous $\left[\mathrm{Ca}^{2+}\right]_{i}$ increases, Mechanical stimulation, $\mathrm{Ca}^{2+}$ waves, Mechanically induced intercellular $\mathrm{Ca}^{2+}$ waves 


\section{Background}

The retinal pigment epithelial (RPE) cells form a monolayer of tightly packed cells which lay between neurosensory retina and the choroid [1]. The RPEs absorb stray light, transport the nutrients from the choroidal side to neural retina, regulate visual cycle and secrete various trophic factors maintaining retinal homeostasis [2].

In pathological conditions RPE dysfunction may lead to the cell layer disruption and choroidal neovascularization as observed in wet age-related macular degeneration (AMD) [3]. AMD is the leading cause of irreversible blindness among the elderly in Western countries. AMD can be divided into dry and wet forms with 80 and 20\% prevalence, respectively. No efficient treatment exists today for dry AMD. Wet AMD development is strongly associated with the vascular endothelial growth factor (VEGF)derived aberrant blood vessels sprout from the choroidal capillaries that penetrate through the Bruch's membrane and RPE into subretinal space. If left untreated, choroidal neovascularization evokes hemorrhage, retinal edema, and increased damage to retinal cells, fibrosis and permanent visual loss due to the undergoing wound healing process. VEGF is the principal therapy target for inhibiting the detrimental neovascularization process, i.e. by intravitreal administration of ranibizumab or bevacizumab or VEGF Trap [4]. Also the intravitreal injection itself may be traumatic and lead to RPE tear and wound healing.

The functionality of RPE after wounding has been assessed in various animal models, for example, rabbit [5, 6], chick [7], porcine [8], bovine RPE [9] and in donor human RPE cells, $[10,11]$ and human ESC-RPE cells [12]. These studies demonstrated that RPE cells on the wound edge undergo dedifferentiation, changing their phenotype towards the phenotype of migrating cells: the cells evolve cytoskeletal reorganization and partially or completely lose their pigmentation $[5,6,8,13]$.

$\mathrm{Ca}^{2+}$ is an important second messenger which mediates vital cellular functions from cell proliferation to cell death. The calcium transients triggered after ATP stimulation are used as a functionality assessment for stem cell derived RPE cells [14, 15]. In addition, $\mathrm{Ca}^{2+}$ is known to play an important role in the wound healing process [16].

Immediately following tissue wounding, intracellular $\mathrm{Ca}^{2+}$ concentration $\left(\left[\mathrm{Ca}^{2+}\right]_{\mathrm{i}}\right)$ increases in the cells located at the edge of the wound. This $\left[\mathrm{Ca}^{2+}\right]_{\mathrm{i}}$ increase then spreads to neighboring cells, forming so-called intercellular $\mathrm{Ca}^{2+}$ wave, which activates undamaged cells, triggers reorganization of cell junctions and coordinates cell motility $[17,18]$.

In RPE cells, $\mathrm{Ca}^{2+}$ controls important physiological processes, such as dark/light adaptation of photoreceptors, phagocytosis, trans-epithelial transport of fluid and ions, secretion of growth factors, as well as and differentiation [19].

RPE cells exhibit spontaneous $\left[\mathrm{Ca}^{2+}\right]_{\mathrm{i}}$ increases that are important for communication with retina $[20,21]$. We have recently shown that human RPE cells have distinct spontaneous $\mathrm{Ca}^{2+}$ activity at different maturation stages. The immature RPEs, where the majority of the cells have fusiform morphology and low level of pigmentation, have lower amount of cells with spontaneous $\left[\mathrm{Ca}^{2+}\right]_{\mathrm{i}}$ increases compared with more mature, cobblestone-shaped, highly-pigmented cells [22].

It has been demonstrated that upon mechanical stimulation of a single cell within a monolayer, RPE cells trigger a $\mathrm{Ca}^{2+}$ wave that originates from the stimulated cell and propagates to neighboring cells [23-25]. Previously, we found that, similarly to 
spontaneous $\left[\mathrm{Ca}^{2+}\right]_{\mathrm{i}}$ increases, the properties of these $\mathrm{Ca}^{2+}$ waves strongly depend on RPE maturation stage. In immature cells, the mechanically induced $\mathrm{Ca}^{2+}$ waves spread far away from the site of stimulation, while in more mature RPE these waves propagate to minute number of cells surrounding the site of stimulation [22].

In wounded monolayers, the cells located in the vicinity of the denuded area are important for triggering a wound healing process $[17,18]$. Furthermore, in the healed wounds, the RPE cells transiently change their morphology towards a less mature phenotype $[5,12,13]$. Thus, we hypothesize that these changes are reflected in $\mathrm{Ca}^{2+}$ dynamics of cells located around the wounded area and inside of healed wounds.

In this paper, we utilized image analysis tool to assess whether wounding and wound healing has effects on $\mathrm{Ca}^{2+}$ dynamics in hESC-RPEs cultured different periods of time. In addition, the effect of culture time on wound speed and time of hESC-RPE cells was evaluated. The knowledge of $\mathrm{Ca}^{2+}$ dynamics in freshly wounded and healed RPE monolayers can shed light on the mechanism of wound healing, and this possibly can be applied to understand the healing process of RPEsin the pathology of wet AMD or its treatment modalities.

\section{Methods}

\section{Differentiation of hESC-RPE cells}

Two hESC lines, Regea08/023 and Regea08/017, that were derived and characterized in our laboratory as described previously [26], were used in this study. The undifferentiated hESC lines were cultured on top of mitotically inactivated, mitomycin $(10 \mu \mathrm{g} / \mathrm{ml}$, SigmaAldrich, St. Louis, USA) treated, human foreskin fibroblasts feeder cells (CRL-2429TM, ATCC, Manassas, VA, USA) [27].

The hESCs were differentiated towards RPE in a RPEbasic medium as cell aggregates for 56-93 days. The selection of pigmented areas from floating aggregates was done manually, isolated areas were dissociated with $1 \times$ Trypsin-EDTA (Lonza, Walkersville, USA), plated with methods described previously, [28] and cultured in average for 85 days (ranging from 28 to 130) to expand amount of cells.

\section{Cell culturing for experiments}

When the amount of cells was sufficient, the hESC-RPE cells were dissociated with $1 \times$ Trypsin-EDTA again and plated on top of Ormocomp-treated (Micro Resist Technology GmbH, Germany) [29], ColIV (Sigma-Aldrich)-coated coverslips (7 $\mathrm{mm}$ in diameter; Thermo Fisher Scientific, Inc., Leicestershire, UK) at a density of $10^{5}$ cells $/ \mathrm{cm}^{2}$. Cells were cultured for a period of $9 \pm 1,16 \pm 1,28 \pm 1$, or $35 \pm 1$ days in RPEbasic medium, during which the medium was replenished thrice a week.

\section{RT-PCR analysis}

The expression of RPE specific genes, the microphthalmia-associated transcription factor (MITF), bestrophin (BEST) and tyrosinase were assessed with reverse transcriptionpolymerase chain reaction (RT-PCR). A housekeeping gene, glyceraldehyde 3-phosphate dehydrogenase (GAPDH) was used as an internal control. The total RNA was extracted from hESC-RPE cells after 9, 16, 28, and 35 days of culture with a NucleoSpin XS-kit (Macherey-Nagel, GmbH \& Co, Duren, Germany) according to the manufacturer's 
instructions. The RT-PCR protocol was carried out as previously reported [28]. The primer sequences, annealing temperatures and product sizes are presented in Table 1.

\section{Quantitative RT-PCR analysis}

The expression of RPE specific genes was further analysed with quantitative RT-PCR by utilising TaqMan ${ }^{\circledR}$ Gene Expression Assays (Applied Biosystems Inc.) with FAM-labeled primers for retinal pigment epithelium specific protein 65 kDa (RPE65, hs01071462_m1) and receptor tyrosine kinase MerTK (MERTK, hs00179024_m1). The glyceraldehyde 3-phosphate dehydrogenase (GAPDH) (Hs99999905_m1) was used as an endogenous control. Samples and negative controls (no template) were run as triplicate reactions using the 7300 Real-time PCR system (Applied Biosystems Inc.) similarly as in Sorkio and others [30]. Thereafter the relative quantification of each gene was calculated with the $2^{-\triangle \Delta C t}$ method [31] using GAPDH expression level of 9-day cultured Regea08/017 as the calibrator for both the 9- and 28-day-cultured Regea08/017, and the GAPDH expression level of 9-day Regea08/023 as the calibrator for both the 9- and 28-day-cultured Regea08/023. For both calibrators the fold change equals 1 .

\section{Immunofluorescence staining and quantification of cell area}

Localization of tight junction-forming Zona Occludens Protein 1 (ZO-1), marker of proliferative cells (Ki67), extracellular matrix forming collagen I (ColI) and laminin (Lam) were assessed with indirect immunofluorescence labeling as described previously [25]. Briefly, the hESC-RPE cells on Ormocomp ${ }^{\circledR}$ coated coverslips were rinsed in PBS thrice and fixed in 4\% paraformaldehyde (Sigma-Aldrich) in 1× PBS (Lonza Group Ltd) for $10 \mathrm{~min}$. Then, the cells were again rinsed with PBS 3 times and permeabilized for $10 \mathrm{~min}$ with $0.01 \%$ Triton X (Sigma-Aldrich) in PBS at RT. Cells were washed thrice in PBS, and unspecific antibody binding sites were blocked with $3 \%$ bovine serum albumin (BSA; Sigma-Aldrich) in PBS at RT for $1 \mathrm{~h}$. Next, the cells were incubated with primary antibodies (see Table 2) dissolved in 0.5\% BSA-PBS for $1 \mathrm{~h}$ at RT, and thereafter were washed thrice with $1 \times$ PBS. Cells were then incubated with secondary antibodies (see Table 2) diluted in $0.5 \%$ BSA-PBS for $1.5 \mathrm{~h}$ at RT. Finally, the cells were washed thrice with PBS and mounted with Vectashield mount with 4',6'diamidino-2-phenylidole (DAPI [Vector Laboratories Inc., Burlingame, CA, USA]). Samples were visualized under Zeiss LSM 700 confocal microscope (Zeiss, Jena, Germany) with a $63 \times$ oil immersion objective or under Olympus IX51 fluorescence microscope with a $20 \times$ air objective. Confocal images were edited with ZEN 2012 black (Zeiss).

Table 1 Reverse-transcriptase-PCR primer sequences, product lengths (bp) and used annealing temperatures

\begin{tabular}{lllrr}
\hline Gene & Forward & Reverse & bp & Tm \\
\hline GAPDH & GTTCGACAGTCAGCCGCATC & GGAATTTGCCATGGGTGGA & 229 & 55 \\
MITF & AAGTCCTGAGCTTGCCATGT & GGCAGACCTTGGTTTCCATA & 352 & 52 \\
BEST & GAATTTGCAGGTGTCCCTGT & ATCAGGAGGACGAGGAGGAT & 214 & 60 \\
Tyrosinase & TGCCAACGATCCTATCTTCC & GACACA GCA AGCTCA CAAGC & 52 & 316 \\
\hline
\end{tabular}

Primer sequences $\left(5^{\prime}>3^{\prime}\right)$ 
Table 2 Primary and secondary antibodies for immunofluorescence staining

\begin{tabular}{lll}
\hline Antibodies & Dilution & Manufacturer \\
\hline | Ab: Mouse-anti-human ZO-1 & $1: 250$ & Life Technologies, Carlsbad, USA \\
| Ab: Ki67 & $1: 500$ & Millipore, Darmstadt, Germany \\
| Ab: Laminin & $1: 100$ & Abcam, Cambridge, UK \\
| Ab: Coll & $1: 250$ & Abcam, Cambridge, UK \\
|| Ab: Alexa Fluor 488 donkey-anti-rabbit & $1: 800$ & Molecular Probes, Leicestershire, UK \\
|| Ab: Alexa Fluor 568 donkey-anti-mouse & $1: 800$ & Molecular Probes, Leicestershire, UK \\
\hline
\end{tabular}

I $A b$ primary antibody, I/ $A b$ secondary antibody

The differences in cell shapes were estimated from cell areas from immunofluorescence images with ZO-1 labeling. In Fiji, the cell borders of 100 randomly selected cells were defined manually for 9-, 16-, 28-, and 35-day-cultured non-wounded cells and inside 7-day-healed wounds of the cells wounded on day 28 of culture. Individual cell areas were calculated with a standard Fiji measurement option. The presented data are combined from Regea08/017 and Regea08/023 hESC-RPEs.

\section{Wounding of hESC-RPEs}

The wounding of day 9- or 28-day cultured hESC-RPE monolayers were done mechanically by performing a linear scratch with a plastic $10 \mu \mathrm{l}$ pipette tip. Although the person who did the injury was always the same and tried to perform it similarly, with same speed and pressure, there might be variation due to the manual handling. When $\mathrm{Ca}^{2+}$ dynamics immediately after wounding was about to be assessed, the cells were allowed to rest for $15 \mathrm{~min}$ after wounding, before the actual experiments were started, thus the samples are abbreviated as 9 days $+15 \mathrm{~min}$ or 28 days $+15 \mathrm{~min}$ samples. When wound healing was evaluated, the cellular monolayers were allowed to grow for 7-8 days prior to the experiments (abbreviated as 9 days +7 days or 28 days +7 days samples). Wound healing process was tracked with time-lapse microscopy in Nikon BioStation CT (Nikon, Nikon Instruments Europe BV, Netherlands). There, the cells were cultured at $37^{\circ} \mathrm{C}$ and $5 \% \mathrm{CO}_{2}$, and phase contrast images of wounded areas were automatically recorded every 1-3 $\mathrm{h}$ during the healing period with a $10 \times$ objective. The medium was replenished thrice a week.

Wound healing speed and time were assessed only from the samples without visible ColIV coating damage. The speed of healing was calculated by analyzing the wound size at the beginning of the assay (in pixels) divided by full healing time in hours. Wound healing time was estimated as time in hours needed for the hESC-RPEs to completely cover the cell-free lane with the cells. The percentage of healed samples was assessed from samples with both damaged and intact ColIV coating. The presented data are combined from Regea08/017 and Regea08/023 hESC-RPEs.

\section{$\mathrm{Ca}^{2+}$ imaging}

The $\mathrm{Ca}^{2+}$ dynamics in cells around fresh wounds ( 9 days +15 min and 28 days +15 min samples) and in healed cultures ( 9 days +7 days and 28 days +7 days samples) was evaluated with live-cell $\mathrm{Ca}^{2+}$ imaging. Two types of measurements were performed on control and wounded hESC-RPEs: first the spontaneous $\mathrm{Ca}^{2+}$ activity was recorded from 
unstimulated cells at least for 5 min time; second, intercellular $\mathrm{Ca}^{2+}$ waves spreading was recorded after mechanical stimulation again at least for 5 min time.

All $\mathrm{Ca}^{2+}$ imaging recordings were performed in HBSS medium, containing $5 \mathrm{mM}$ glucose, $20 \mathrm{mM}$ HEPES, $0.44 \mathrm{mM} \mathrm{KH}_{2} \mathrm{PO}_{4}, 137 \mathrm{mM} \mathrm{NaCl}, 5 \mathrm{mM} \mathrm{KCl}, 4.2 \mathrm{mM} \mathrm{NaHCO}{ }_{3}$, $1.2 \mathrm{mM} \mathrm{MgCl}_{2}$, and $2 \mathrm{mM} \mathrm{CaCl}_{2}$. pH was adjusted to 7.37 with $3 \mathrm{M} \mathrm{NaOH}$; osmolarity was adjusted to $335 \pm 5 \mathrm{mOsm} / \mathrm{kg}$ with sucrose. All components were from Sigma-Aldrich.

For the live-cell $\mathrm{Ca}^{2+}$ imaging recordings hESC-RPEs were loaded with Fluo-4-acetoxymethyl ester (Fluo-4 AM; $4 \mu \mathrm{M}$, in $1 \mathrm{~h}$ incubation at room temperature (RT), Life Technologies, Carlsbad, USA). Next, the cells were washed with HBSS thrice. The coverslips with Fluo-4 AM loaded cells were then mounted on a perfusion chamber (Warner Instruments, Hamden, USA) and filled with HBSS. The recording of the fluorescence signal was done under an Olympus IX51 fluorescence microscope (Olympus, Tokyo, Japan) with ANDOR iXion 885 camera (Oxford Instruments, Oxfordshire, UK). Fluo-4 AM was excited at $490 \mathrm{~nm}$ (bandwidth $15 \mathrm{~nm}$ ) with Polychrome $V$ at $30 \%$ light intensity (TILL Photonics, Pittsburgh, USA) with an exposure time of $20 \mathrm{~ms}$; the emission was collected at 510-560 nm. The recording was done at a rate of 2 frames per second with the binning of $2 \times 2$ with Live Acquisition software v. 2.4.0.13 (FEI Munich GmbH), at least for $5 \mathrm{~min}$ (600 frames) time. From each individual fluorescence time-series a corresponding brightfield images were taken to assess cell morphology.

The mechanical stimulation was induced by touching single hESC-RPE cell with a glass micropipette during the recording of $\mathrm{Ca}^{2+}$ activity, similarly as described above. The micropipette was made from a glass capillary (Biomedical Instruments, Zollnitz, Germany; $0.8691 .50980 \mathrm{~mm}$ ) with a Narishige pipette puller. The micropipette was mounted on a Luigs \& Neumann SM 5-9 vertical microinjection system (Luigs \& Neumann, Ratingen, Germany) and intermittently lowered to touch a target cell membrane [25]. In samples with fresh wounds ( 9 days $+15 \mathrm{~min}$ and 28 days $+15 \mathrm{~min}$ ), the site for mechanical stimulation was chosen to be in the vicinity to the wound edge. In samples with healed or partially healed wounds ( 9 days +7 days and 28 days +7 days), the stimulated cell belonged to the healed area.

All experiments were performed at RT at least 4 times. For each wounded area, the non-wounded area from the same coverslip was used as a control. The presented data are combined from Regea08/017 and Regea08/023 hESC-RPEs.

\section{$\mathrm{Ca}^{2+}$ imaging data analysis}

The recorded time-series were analyzed with our in-house Matlab (R2013 A, Mathworks) algorithms and Fiji [32].

The cells on fluorescence time-series images were identified as described in [22]. At first cell centers were detected from averaged fluorescence images in Matlab with inhouse algorithm developed for this purpose. Thereafter, cells were approximated as fixed-sized circles in Fiji [32]. The cells with immature, fusiform morphology, this fitting was done manually in Fiji. Next, average fluorescence kinetics from each detected cell at every recorded time point was extracted in Fiji and exported to Matlab for further analysis. 
In Matlab, the fluorescence kinetics from single cells was corrected for background fluorescence and smoothed with a moving average algorithm with the 5 points span. Then, baselines in the beginning and in the end of a recording were automatically detected for each cell, and the fluorescence curves were corrected for bleaching and normalized to initial baseline levels. Finally, the peaks in the fluorescence curves were automatically detected. The amplitude of peak threshold was set to 1.1 (10\% higher than the baseline). The cell identification and fluorescence curves analysis algorithms together with Matlab codes were similar to the ones used in Abu Khamidakh et al. [22]. The fluorescence kinetics from single cells was corrected for background fluorescence and smoothed with a moving average algorithm with the 5 points span. The fluorescence values were corrected for bleaching with the normalizing value achieved by comparing baselines in the beginning and in the end of a recording from each cell. Finally, the peaks in the fluorescence curves were automatically detected. The amplitude of peak threshold was set to 1.1 (10\% higher than the baseline).

The spontaneous activity of hESC-RPEs was assessed as the percentage of cells with spontaneous $\left[\mathrm{Ca}^{2+}\right]_{\mathrm{i}}$ increases (\%RC-percentage of responsive cells). In wounded samples, the cellular monolayer in the field of view was divided into several areas: 1- "Wound" area included the cells in the healed part of a monolayer (analyzed from samples that were fully or partially healed during the 7-day healing time), 2- "Area 1" included cells directly adjacent to the wound (within a distance of 40-60 $\mu \mathrm{m}), 3-$ "Area 2" consisted of cells directly adjacent to "Area 1" (40-60 $\mu \mathrm{m}$ distance), 4-"Area 3" included cells that immediately followed "Area 2" (40-60 $\mu \mathrm{m}$ distance). The cells belonging to each area were automatically detected with an inhouse algorithm developed for this purpose.

The spreading of mechanically induced $\mathrm{Ca}^{2+}$ waves was estimated by identifying cells that were participated in the wave. Any two cells were considered to propagate a wave, if they had fluorescence peaks with a peak time difference of less than $4 \mathrm{~s}$, and the distance between these cells was less than 2-3 characteristic cell sizes [22]. Only the cells that had a fluorescence peak and which were connected to the cell/site of mechanical stimulation via other cells having fluorescence peak were considered to be involved in a wave. Cell clusters with small $\mathrm{Ca}^{2+}$ waves that were disconnected from the site of mechanical stimulation were considered as spontaneous $\mathrm{Ca}^{2+}$ waves. The extent of $\mathrm{Ca}^{2+}$ wave spreading was assessed by calculating a total number of cells propagating a $\mathrm{Ca}^{2+}$ wave and by estimating the area in the field of view that was covered by the wave. The presented data are combined from Regea08/017 and Regea08/023 hESC-RPEs.

\section{Ethical issues}

University of Tampere has the approval of the National Authority for Medicolegal Affairs Finland (TEO) to study human embryos (Dnro 1426/32/300/05) and a supportive statement of the Ethical Committee of the Pirkanmaa Hospital District to derive, culture, and differentiate hESC lines from surplus human embryos (R05116). No new lines were derived for this study. 


\section{Statistics}

The statistical significance between healed cell areas, and differences in wound healing time and speed was done with two-sample unpaired Student's $t$ test. The number of cells involved in a mechanically induced $\mathrm{Ca}^{2+}$ wave, or area of $\mathrm{Ca}^{2+}$ wave spreading in different groups was done with Mann-Whitney test. The $\mathrm{p}<0.05$ was considered statistically significant. The results were expressed as mean \pm standard error of mean (SEM). Number of samples is referred to as $n_{s}$ in the figure legends.

\section{Results}

\section{Morphology and differentiation status of wounded and intact hESC-RPE cells}

Differentiation status of 9-, 16-, 28-, and 35-day-cultured hESC-RPE cells was evaluated with RT-PCR. The samples from both Regea08/017 and Regea08/023 cell lines expressed RPE-specific markers MITF, bestrophin and Tyrosinase (Fig. 1A, B). The maturation status was further assessed with quantitative RT-PCR with two RPE specific genes. The expression of both RPE65 and MERTK was very low (i.e. the target gene Ct:s were approximately 30), still there was a detectable increase in RPE65 and MERTK mRNA expression when the 9 day and 28 day cultured samples were compared together. The morphology and pigmentation of representative 9-, 16-, 28-, and 35-day-cultured cells from both cell lines is represented on bright field images in Fig. 1E-H (Regea08/017) and Fig. 1I-L (Regea08/023).

The cultures were labelled with the tight junction protein $\mathrm{ZO}-1$ antibody to visualize the cell confluence and polarization (Fig. 2). Indirect immunofluorescence staining showed that Regea08/017 hESC-RPE cells expressed ZO-1 on cell junctions in control non-wounded samples (Fig. 2A-C), as well as in wounded and healed samples (Fig. 2DF), although the cells surrounding the wound still had elongated i.e. fusiform shaped morphology. The Regea08/023 hESC-RPE samples (Fig. 2G-L) were similar to the Regea08/023 hESC-RPEs.

The presence of proliferating cells was evaluated by labeling cultures with Ki67 antibody. There were no Ki67 positive cells in Regea08/017 hESC-RPE the control cultures (Fig. 2A-C). In wounded Regea08/017 cultures that were partially healed on day 7 after wounding, there were only few Ki67 positive cells (Fig. 2D-F) which located close to the edge, but not on the $1^{\text {st }}$ rim of cells lining the wound. In the Regea08/023 monolayer, there were no dividing, i.e. Ki67 positive cells either in control or wounded and 7 days healed samples were found (Fig. 2J-1).

Because migration and wound healing depends on the cell substrata, [33] we next assessed the localization of laminin and ColI. We saw that Regea08/017 hESC-RPEs produced laminin in control cultures (Fig. 3A-C). After wounding cells produced a thin layer of ColI (Fig. 3D-F). In the wounded and healed culture of Regea08/023 hESC-RPE cells produced a clearly marked layer of ColI (Fig. 3J-L). The deposition of COLI labelling close to the substrata (arrows on the orthopanels), and low background labelling in other areas of the cells are presented in Additional file 1: Fig S1.

Because the culture time influences the morphology of the cells, we analyzed cell sizes by measuring the cell areas in 9-, 16-, 28-, and 35-day-cultured hESC-RPEs and in cells inside healed wounds in 28 days +7 days samples. An example of manual cell border 


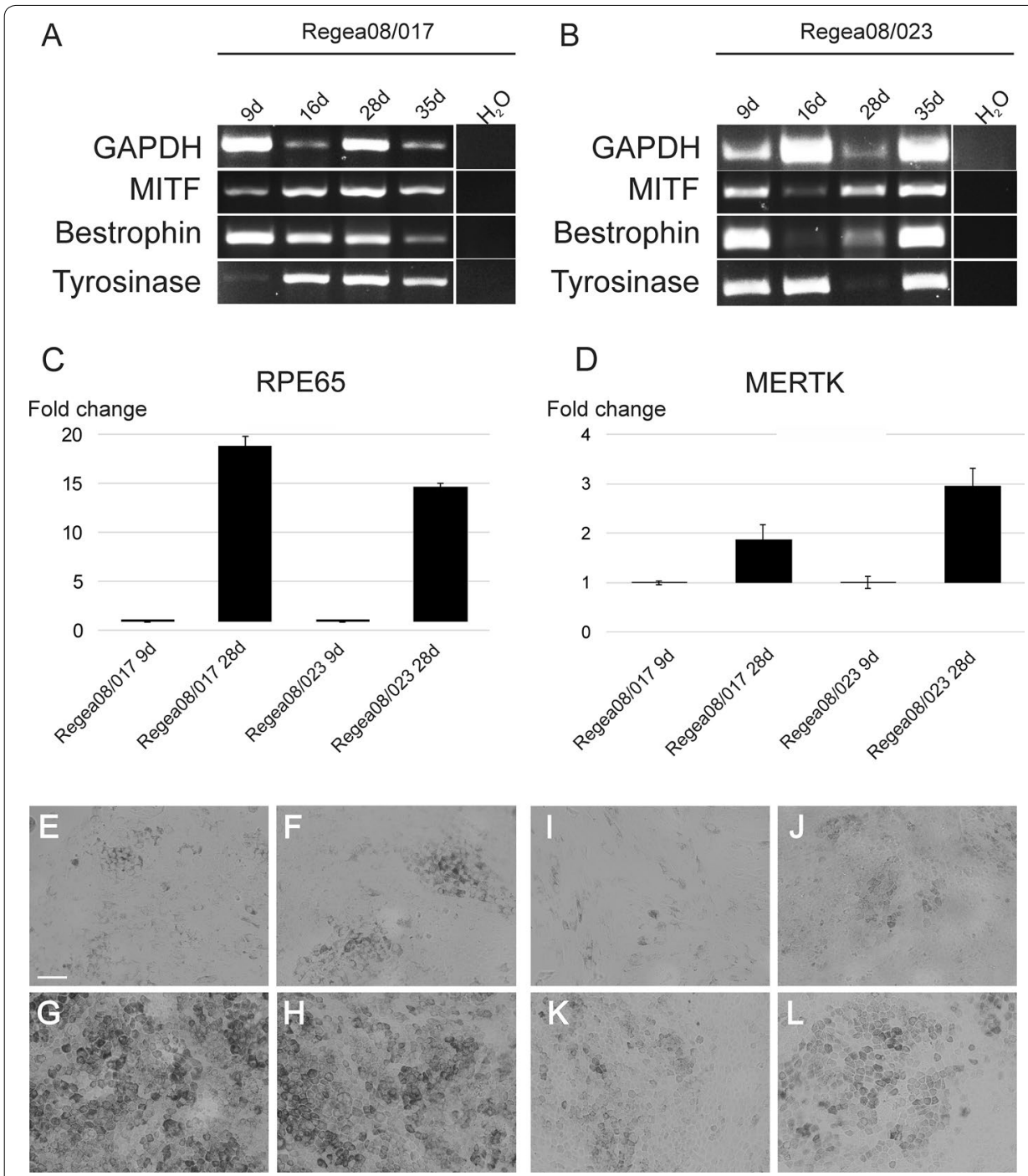

Fig. 1 Gene expression analysis and morphology of hESC-RPE cells. Gene expression of a house-keeping gene GAPDH, and RPE-specific marker genes MITF, bestrophin and tyrosinase were assessed with reverse transcription-polymerase chain reaction (RT-PCR) from Regea08/017 (A) and Regea08/023 (B) hESC-RPE cells cultured for $9,16,28$, and 35 days. Water was used as negative control. Relative gene expression of mature RPE markers, the retinal pigment epithelium specific protein $65 \mathrm{kDa}$ (RPE65) (C) and receptor tyrosine kinase MerTK (MERTK) (D) of 9-day and 28-day cultured non-wounded (i.e. control) samples. The Ct values of target genes were approximately 30. A bright filed image of Regea08/017 hESC-RPEs cultured for 9 days (E), 16 days (F), 28 days $(\mathbf{G})$, and 35 days (H). Bright filed image of Regea08/023 hESC-RPEs cultured for 9 days (I), 16 days (J), 28 days (K), and 35 days (L). Scale bar $50 \mu \mathrm{m}$

segmentation is presented in Fig. 4a. Figure $4 \mathrm{~b}$ indicates that cells wounded on the day 28 of culture have the same size inside the healed wounds after 7 days as 9-day-cultured cells. In the Table 3 are all $p$-values of presented datasets.

\section{Wound healing speed of hESC-RPEs}

To assess wound healing capabilities of hESC-RPE cells, the 9- and 28-day-cultured cells were followed for 7-8 days post-wounding. Both wounded 9- and 28-day-cultured hESC-RPEs were able to heal by filling denuded areas with cells (Fig. 5A-C). 


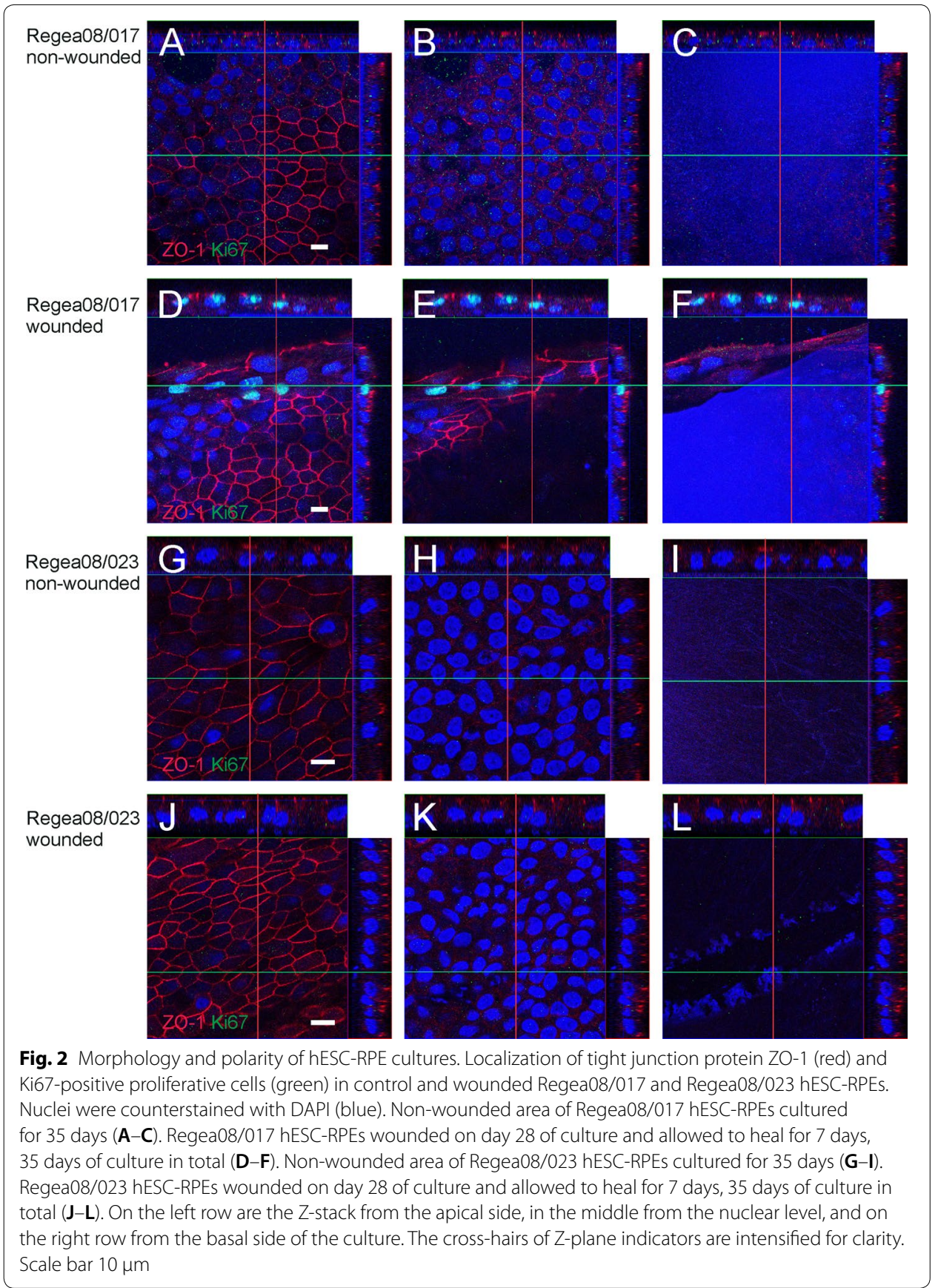

Samples, where ColIV coating was damaged during wounding, had significantly poorer ability to heal (Fig. 5D). When no visible ColIV damage occurred during the wounding process, $100 \%$ of samples wounded on day 9 of culture and $61 \%$ of samples wounded on day 28 were able to heal. The monolayers wounded on day 9 healed almost 3 times faster compared to those wounded on day $28\left(p=2 \times 10^{-6}\right)$ (Fig. 5E). The full healing time of wounded 9-day-cultured hESC-RPEs was $20 \pm 3 \mathrm{~h}$, while 28-day-cultured cells healed 2.5 -fold slower with a healing time of $49 \pm 9 \mathrm{~h}$ $(p=0.002)$. (Fig. 5F). 


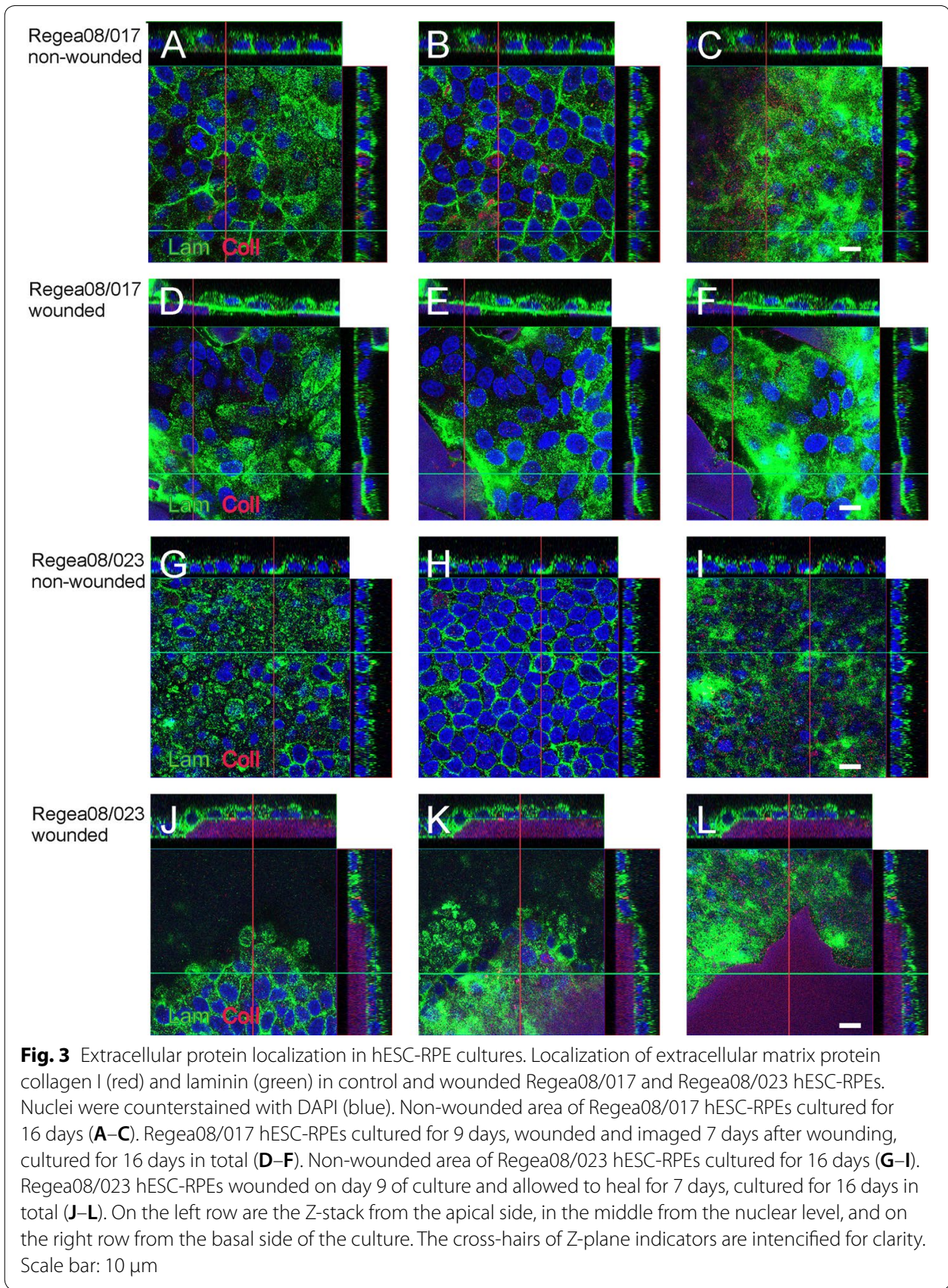

\section{Spontaneous $\left[\mathrm{Ca}^{2+}\right]_{\mathrm{i}}$ increases in wounded hESC-RPEs}

Then, the effect of wounding on spontaneous transient $\left[\mathrm{Ca}^{2+}\right]_{\mathrm{i}}$ increases was evaluated. The samples of $9 \mathrm{~d}+15 \mathrm{~min}$ (Fig. 6A-C), 9 days +7 days (Fig. 6D-F), 28 days $+15 \mathrm{~min}$ (Fig. 6G-I), and 28 days +7 days (Fig. 6J-L) samples are in Fig. 6. On the left are the representative bright field images, in the middle are the corresponding fluorescence images of the cells in the same field of view loaded with Fluo-4 AM are shown, and on the right are the analysed areas, where the percentage of the cells with spontaneous $\left[\mathrm{Ca}^{2+}\right]_{\mathrm{i}}$ increases (\%RC) were compared. In 9-day-cultured hESC-RPE cells with fresh wounds ( 9 days +15 min samples), \%RC in the area closest to the wound edge ("area 1") was 

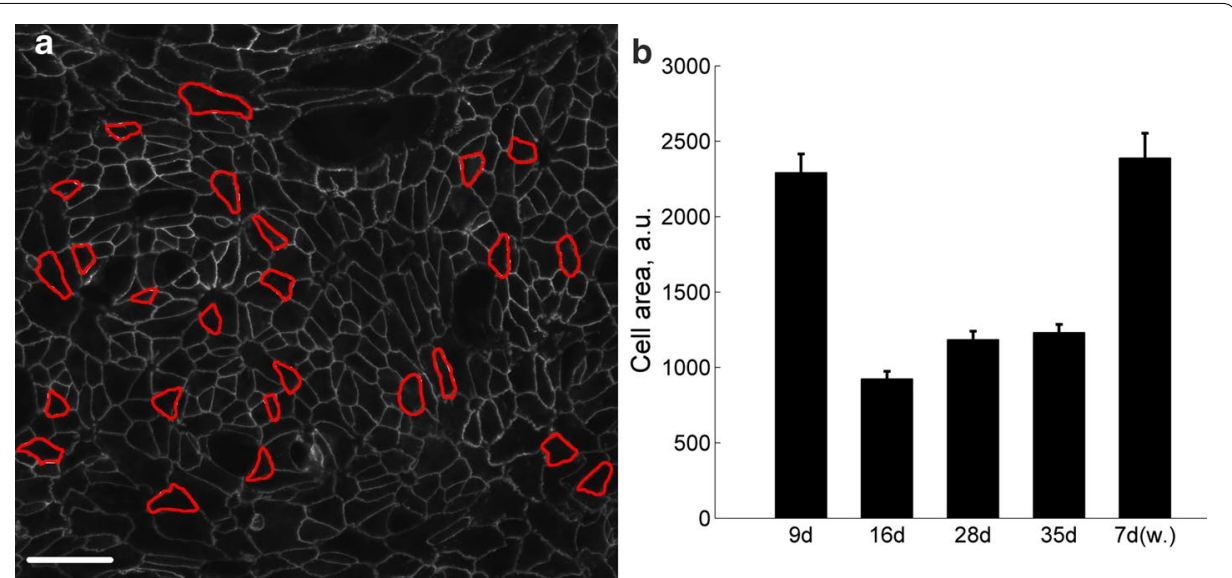

Fig. 4 Cell size differences in 9- to 35-day-cultured hESC-RPE. Cell area was analyzed by manual cell boarder segmentation indicated by red lines (a). Scale bar: $50 \mu \mathrm{m}$. Analysis of cell areas (b) of hESC-RPEs cultured for 9 days $\left(n_{s}=4\right), 16$ days $\left(n_{s}=6\right), 28$ days $\left(n_{s}=6\right)$ or 35 days $\left(n_{s}=5\right)$, and 28-day-cultured hESC-RPEs, wounded and visualized 7 days after wounding ( 7 days) $\left(n_{s}=2\right)$. The presented data are combined from Regea08/017 and Regea08/023 hESC-RPEs

Table $3 p$-values calculated with the unpaired Student's two-sample t-test for datasets presented in Fig. 4

\begin{tabular}{|c|c|c|c|c|c|}
\hline$p$ & 9 days & 16 days & 28 days & 35 days & 7 days w. \\
\hline 9 days & - & & & & \\
\hline 16 days & $2.33 \times 10^{-20}$ & - & & & \\
\hline 28 days & $2.08 \times 10^{-14}$ & $4.94 \times 10^{-04}$ & - & & \\
\hline 35 days & $1.44 \times 10^{-13}$ & $3.48 \times 10^{-05}$ & 0.541 & - & \\
\hline 7 days w. & 0.636 & $3.30 \times 10^{-15}$ & $4.67 \times 10^{-11}$ & $1.94 \times 10^{-10}$ & - \\
\hline
\end{tabular}

Samples are abbreviated as follows: "9 days"-9-day-cultured;"16 days"-16-day-cultured; "28 days"-28-day-cultured; "35 days"-35-day-cultured;"7 days w."-7-day-cultured cells within wounds made on day 28

more than twice higher compared to control (\%RC in area $1=33.2 \pm 6.4 \%$; $\% \mathrm{RC}$ in control $=15.3 \pm 4.4 \% ; p=0.028$ ) (Fig. $6 \mathrm{C}$ ). The 9 days +7 days (Fig. $6 \mathrm{~F}$ ) and 28 days $+15 \mathrm{~min}$ samples (Fig. 6I) did not have statistically significant changes in \%RC in any of the investigated areas. Healed or partially healed hESC-RPEs that were wounded on day 28 of culture and then allowed to heal for 7 days ( 28 days +7 days samples) had almost twofold decreased \% RC inside the healed wound compared to the control (\%RC in the healed wound area $=19.7 \pm 4.6$; $\% \mathrm{RC}$ in control $=38.7 \pm 2.0 \%$; $p=0.029$ ) (Fig. $6 \mathrm{~L}$ ).

\section{Mechanically induced $\mathrm{Ca}^{2+}$ waves in wounded hESC-RPEs}

Next, the effect of wounding on the propagation of intercellular $\mathrm{Ca}^{2+}$ waves induced by mechanical stimulation was assessed. Mechanical stimulation of a single cell in a hESC-RPE monolayer resulted in a $\left[\mathrm{Ca}^{2+}\right]_{\mathrm{i}}$ increase in the stimulated cell that propagated in a wave-like manner to neighboring cells in 9 days $+15 \mathrm{~min}, 9$ days +7 days, 28 days +15 min, and 28 days +7 days samples.

The wounded hESC-RPE monolayer ( 9 days +7 days) and a shadow of a micropipette used for mechanical stimulation is represented in Fig. 7A and the fluorescence image of the same culture loaded with $\mathrm{Ca}^{2+}$-sensitive dye in the same field of view is shown 


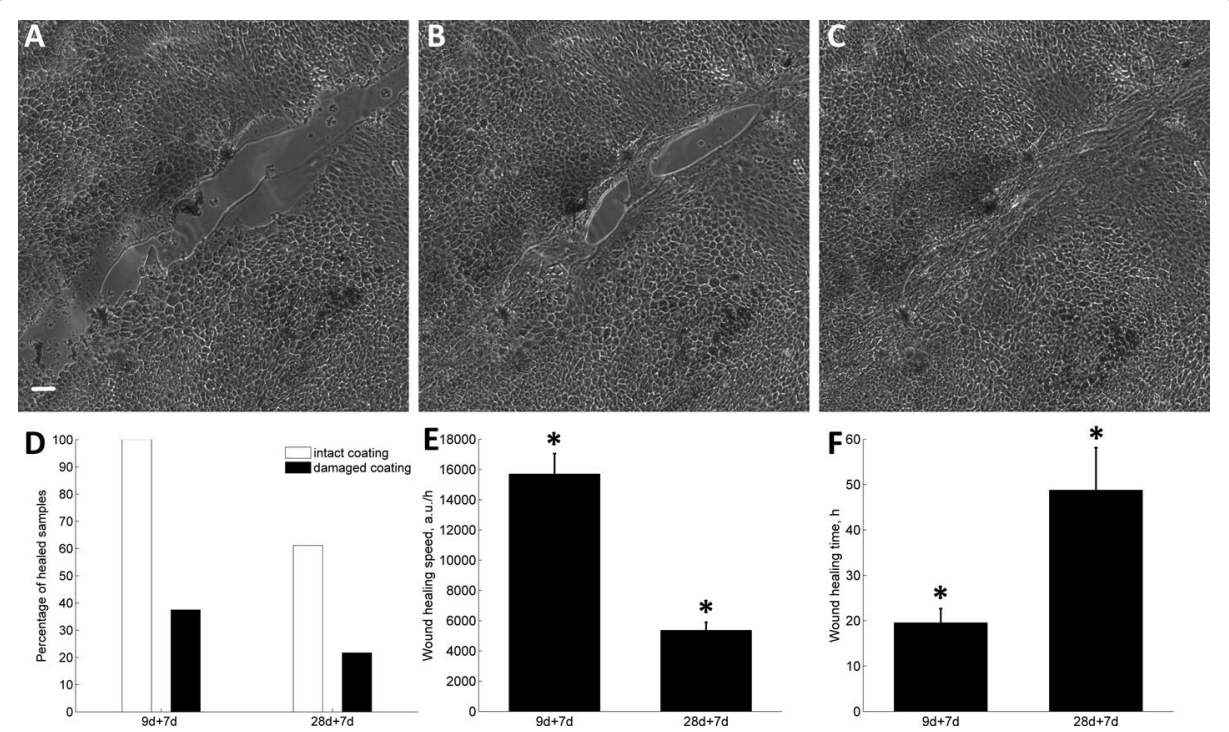

Fig. 5 Wound healing speed and time. Bright field image of Regea08/023 hESC-RPEs wounded on day 28 of culture, then healed for 7 days, visualized immediately after wounding (A), $58 \mathrm{~h}$ after wounding (B), and $118 \mathrm{~h}$ after wounding (C). Scale bar: $50 \mu \mathrm{m}$. Percentage of completely healed samples (white bar-intact coating; black bar-damaged coating) wounded on day 9 and healed for 7 days (coating intact, $n_{s}=16$; coating damaged, $n_{s}=8$ ) or wounded on day 28 and healed for 7 days (coating intact, $n_{s}=18$; coating damaged, $\left.n_{s}=23\right)(\boldsymbol{D})$. Wound healing speed during a 7-day follow-up of 9- $\left(n_{s}=16\right)$ or 28-day-cultured $\left(n_{s}=11\right)$ hESC-RPEs $(\mathbf{E})$. Wound healing time during a 7-day follow-up of 9- $\left(n_{s}=16\right)$ or 28-day-cultured $\left(n_{s}=11\right)$ hESC-RPE cells $(\mathbf{F})$. The presented data are combined from Regea08/017 and Regea08/023 hESC-RPEs

in Fig. 7B, see also corresponding Additional file 2: Video S1. The white polygon indicates the area of wave spreading, and cells indicated with white dots are the cells participating in the wave propagation. A representative brightfield images with a wounded hESC-RPE monolayer and a shadow of a micropipette used for mechanical stimulation is represented in Fig. 7C (the 28 days +7 days) and the fluorescence image of the same culture loaded with $\mathrm{Ca}^{2+}$-sensitive dye in the same field of view is shown in Fig. 7D, see also corresponding Additional file 3: Video S2. The latter figure also indicates the area of $\mathrm{Ca}^{2+}$ wave spreading (white polygon) and the cells participating in the wave propagation (white dots).

Samples that were cultured for 28 days prior to wounding and later allowed to heal for 7 days ( 28 days +7 days samples) showed a 4.6-fold higher number of cells involved in $\mathrm{Ca}^{2+}$ wave spreading within a healed area compared to control ( $79 \pm 19$ cells in wounded area and $17 \pm 6$ cells in control area; $p=0.0047$ ) (Fig. 7E). Furthermore, in these samples $\mathrm{Ca}^{2+}$ waves covered 8.9-fold larger areas compared to control ( $\left.p=0.0023\right)$ (Fig. 7F).

In $9 \mathrm{~d}+15$ min, 9 days +7 days, and 28 days +15 min samples $\mathrm{Ca}^{2+}$ waves inside or close to the wounded areas propagated in the same manner as in non-wounded controls (Fig. 7E, F.

\section{Discussion}

The complex RPE-derived wound healing process in AMD is weakly understood. In a recent study the healing of scratch wounded H9 hESC-RPE cells has been shown to have partial wound closure within 30 days [12]. $\mathrm{Ca}^{2+}$ has an important role in 

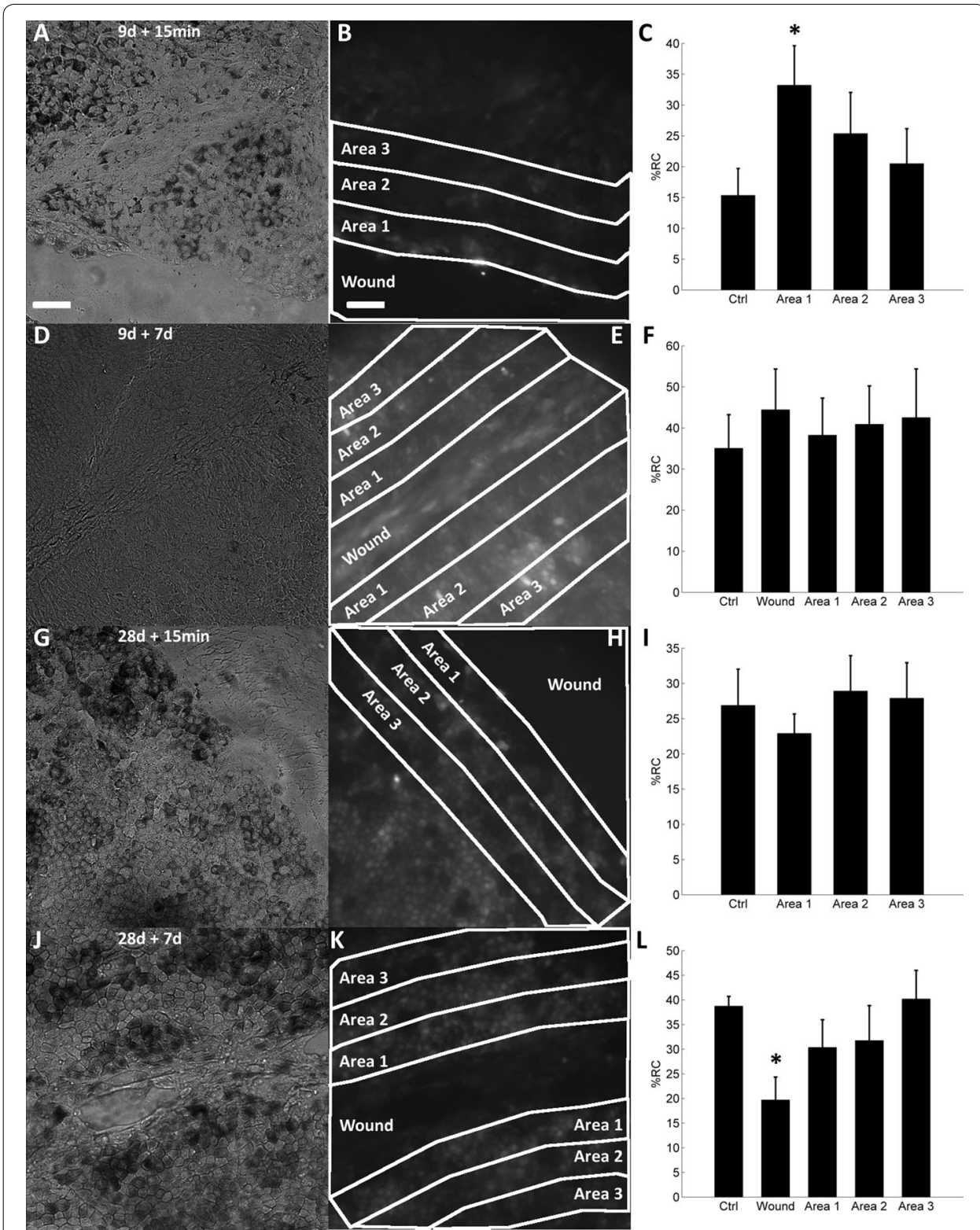

Fig. 6 Percentage of cells with spontaneous $\left[\mathrm{Ca}^{2+}\right]_{\mathrm{i}}$ increases (\%RC) in wounded hESC-RPEs at different areas related to the wound location. A bright field image of 9-day-cultured, wounded hESC-RPEs, visualized immediately after wounding (A). A fluorescence image of the same sample as in $\mathbf{A}$ loaded with $\mathrm{Ca}^{2+}{ }^{2}$-sensitive indicator Fluo-4 AM (B). The wound area ("wound") and adjacent areas ("Area 1","Area 2", "Area 3") are marked with white lines. Analyzed percentage of responsive cells (\%RC) in non-wounded control $\left(n_{s}=8\right)$, and area 1 $\left(n_{s}=8\right)$, area $2\left(n_{s}=8\right)$ and area $3\left(n_{s}=8\right)(C)$. Statistical significance: $p<0.05$ is marked with Asterisk. A bright field image of 9-day-cultured then wounded hESC-RPEs, visualized 7 days after wounding (D). A fluorescence

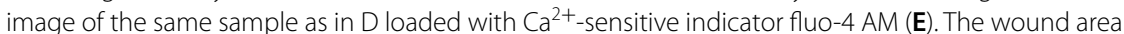
and adjacent areas are marked with white lines. The \%RC in non-wounded control $\left(n_{s}=8\right)$, wounded area $\left(n_{s}=8\right)$ and area $1\left(n_{s}=8\right)$, area $2\left(n_{s}=8\right)$, and area $3\left(n_{s}=6\right)(\mathbf{F})$. A bright field image of 28-day-cultured and wounded hESC-RPEs, visualized immediately after wounding $(\mathbf{G})$. A fluorescence image of the same

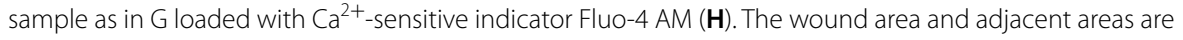
marked with white lines. The \%RC in non-wounded control $\left(n_{s}=8\right)$ and area $1\left(n_{s}=8\right)$, area $2\left(n_{s}=8\right)$, and area $3\left(n_{s}=8\right)(\mathbf{I})$. A bright field image of 28-day-cultured then wounded hESC-RPEs, visualized 7 days after wounding $(\mathbf{J})$. A fluorescence image of the same sample as in $\mathrm{J}$ loaded with $\mathrm{Ca}^{2+}$-sensitive indicator Fluo-4 AM (K). The wound area and adjacent areas are marked with white lines. The \%RC in non-wounded control $\left(n_{s}=4\right)$, wounded area $\left(n_{s}=4\right)$ and area $1\left(n_{s}=4\right)$, area $2\left(n_{s}=4\right)$, and area $3\left(n_{s}=4\right)(\mathbf{L})$. The presented data are combined from Regea08/017 and Regea08/023 hESC-RPEs 


\section{(See figure on next page.)}

Fig. $7 \mathrm{Ca}^{2+}$ wave propagation in wounded hESC-RPEs after mechanical stimulation. A bright field image of a hESC-RPE monolayer $(9 d+7 d)(\mathbf{A})$. The dark shadow of micropipette lowered towards the cell to perform mechanical stimulation can be seen. Fluorescence image of the same culture as in A loaded with fluorescent $\mathrm{Ca}^{2+}$ sensitive dye Fluo-4 AM that reflects $\left[\mathrm{Ca}^{2+}\right]_{i}$ concentration in the cytoplasm (B). A white line indicates the area of the monolayer that responded to single-cell mechanical stimulation. White dots indicate the cells that participate in a mechanically induced $\mathrm{Ca}^{2+}$ wave. Similarly a bright field image of a hESC-RPE monolayer ( 28 days +7 days) (C). The dark shadow of micropipette lowered towards the cell to perform mechanical stimulation can be seen. Fluorescence image of the same culture as in A loaded with fluorescent $\mathrm{Ca}^{2+}$ sensitive dye Fluo-4 AM that reflects $\left[\mathrm{Ca}^{2+}\right]_{\mathrm{i}}$ concentration in the cytoplasm (D). A white line indicates the area of the monolayer that responded to single-cell mechanical stimulation. White dots indicate the cells that participate in a mechanically induced $\mathrm{Ca}^{2+}$ wave. Number of $\mathrm{hESC}$-RPE cells participating in a mechanically induced intercellular $\mathrm{Ca}^{2+}$ wave in wounded 9-day-cultured cells followed for $15 \mathrm{~min}$ (ctrl, $\mathrm{n}_{\mathrm{s}}=7$; wounded, $n_{s}=7$ ), or for 7 days ( $c t r l, n_{s}=7$; wounded, $n_{s}=7$ ). The mechanically induced intercellular $\mathrm{Ca}^{2+}$ wave in wounded 28-day-cultured cells followed for $15 \min \left(\mathrm{ctrl}, \mathrm{n}_{\mathrm{s}}=8\right.$; wounded, $\mathrm{n}_{\mathrm{s}}=8$ ), or for 7 days (ctrl, $n_{s}=6$; wounded, $n_{s}=7$ ). E White bar-control; black bar-wound edge or healed wound. Statistical significance: $p<0.05$ is indicated with Asterisk. Area of a mechanically induced intercellular $\mathrm{Ca}^{2+}$ wave spreading in wounded 9-day-cultured cells followed for $15 \mathrm{~min}$ (ctrl $n_{s}=7$; wounded, $n_{s}=7$ ), or for 7 days (ctrl, $n_{s}=7$; wounded, $n_{s}=7$ ). The mechanically induced intercellular $\mathrm{Ca}^{2+}$ wave spreading in wounded 28-day-cultured cells followed for $15 \mathrm{~min}$ (ctrl, $n_{s}=8$; wounded $n_{s}=8$ ), or for 7 days (ctrl, $n_{s}=6$; wounded, $n_{s}=7$ ). F White bar-control; black bar-wound edge or healed wound. Statistical significance: $p<0.05$ is indicated with Asterisk. The presented data are combined from Regea08/017 and Regea08/023 hESC-RPEs

the wound healing of epithelial cells but less is known about cellular $\mathrm{Ca}^{2+}$ dynamics implicated in the response to fresh wounds and wound healing of RPE. Here, we analyzed spontaneous and mechanically induced $\left[\mathrm{Ca}^{2+}\right]_{\mathrm{i}}$ increases of cells in freshly wounded and healed hESC-RPE monolayers at two different maturation stages. There are great expectations of hESC-RPE as becoming cell source for cell replacement therapy [34-36]. To understand the integration of surgical transplants, it is essential to study the wound healing mechanisms of the hESC-RPEs.

For RPE cells, the ability to heal scratch wounds has been demonstrated in different in vitro and in vivo models, e.g. in [5, 7-9, 12]. For hESC-RPE cells, Schwartz et al. showed that, in vitro, their attachment to substrata strongly depends on cell differentiation stage: the lighter pigmented cells attach and proliferate better than heavily pigmented cells. Thus, it was proposed that less mature cells may provide better results for transplantation studies [37]. In line with the latter, we found that wound healing capacity of our hESC-RPEs depended on cell culture time: cells wounded after 9-days of culture showed a higher percent of healed samples and faster healing speed compared to those wounded on 28-day of culture. Substratum is crucial for wound healing: the percentage of healed samples with damaged collagen IV coating was much lower compared to that with intact coating in hESC-RPE cells wounded on both day 9 and day 28 after plating. This is in line with the knowledge that cells in general prefer the extracellular matrix substrata and that the plain Ormocomp coating does not support hESC-RPE cell spreading [29]. In addition, with confocal orthoimages, we showed that within 7 days the cells had produced new extracellular matrix layer with laminin and collagen I to the site of the wound and had migrated on top of it. In confocal analyses this layer appeared to be thicker than the extracellular matrix prior to the wounding.

In epithelial monolayers, several rows of cells behind the wound edge participate in wound healing, pushing the monolayer towards the denuded area [38-40]. In chick 


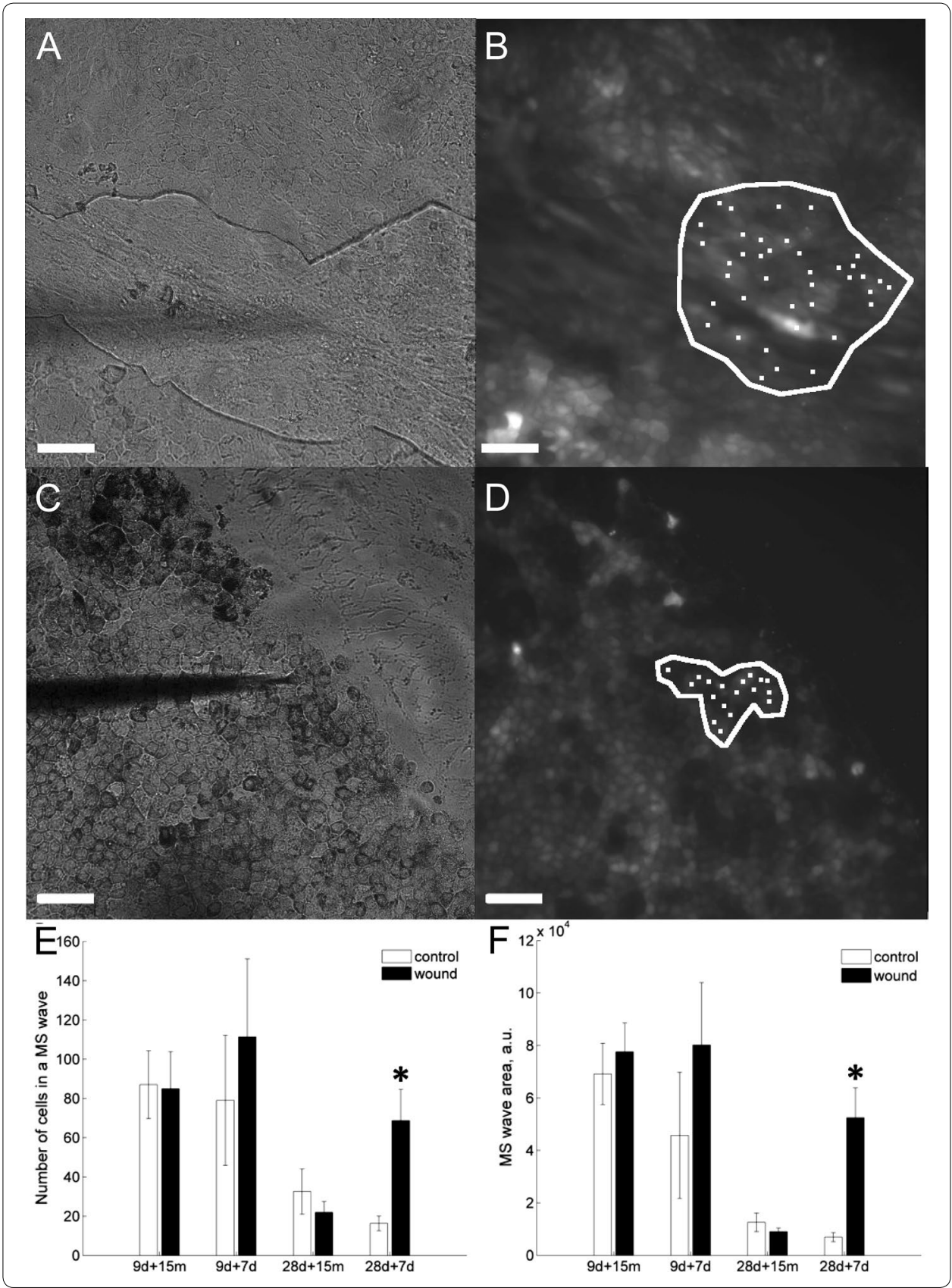

model of small wounds, the RPE cells stretch from wound edges towards each other and then fill the wound without proliferation [7]. But, if the wound is wide, RPE cells start proliferating to seal it [7]. In accordance with these data, we saw hESC-RPE cells which were proliferating during wound healing, but there were no proliferating cells after the wound closure. In cultures with proliferating cells, the Ki-67 positive cells located few cell layers away from the wound edge.

The scratch-wounding of a cellular monolayer is known to trigger an intercellular $\mathrm{Ca}^{2+}$ wave that spreads several rows away from the leading wound edge [18, 41-43]. For example in human corneal epithelial cells, it has been shown that ATP released 
at the time of injury serves as an early signal that enables activation of wound healing processes [44]. In our 9-day cultured hESC-RPEs, after wounding we detected the elevated percentage of cells with spontaneous $\left[\mathrm{Ca}^{2+}\right]_{\mathrm{i}}$ increases close to the wound edge. Thus, in this study, we could also observe distinct behavior of the cells near the denuded area in terms of $\mathrm{Ca}^{2+}$ dynamics compared to the rest of the monolayer. We can hypothesize that the initial $\mathrm{Ca}^{2+}$ wave which occurs at the time of wounding affects the $\mathrm{Ca}^{2+}$ dynamics of the cells close to the wound edge to promote the healing.

In freshly wounded 28-day-cultured cells, the percentage of cells with spontaneous $\left[\mathrm{Ca}^{2+}\right]_{\mathrm{i}}$ increases was the same as in control, regardless of the distance to the wound edge. We hypothesize that 28-day-cultured hESC-RPEs are not able to make their spontaneous activity any higher, as previously we have shown that the percentage of cells with spontaneous $\left[\mathrm{Ca}^{2+}\right]_{\mathrm{i}}$ increases does not elevate further after day 28 of culture [22].

Here, the hESC-RPEs wounded on day 28 of culture and then allowed to heal for 7 days, had lower percentage of cells with spontaneous $\left[\mathrm{Ca}^{2+}\right]_{i}$ increases inside the healed area. This finding is in accordance with our previously published observation that the percentage of cells with spontaneous $\left[\mathrm{Ca}^{2+}\right]_{i}$ increases raises during maturation in hESC-RPE cells [22]. Thus, cells with shorter culture time within the healed wounds have lower spontaneous $\mathrm{Ca}^{2+}$ activity compared to surrounding cells, which have been cultured for a longer period of time.

Mechanical stimulation has been shown to induce intercellular $\mathrm{Ca}^{2+}$ waves in RPE [22-25]. In rat RPE, the mechanically induced intercellular $\mathrm{Ca}^{2+}$ waves spread to up to 3 cell tiers away from the site of mechanical stimulation [23, 24], whereas in human ARPE-19 cell line, such waves are more intense, covering up to 14 cell layers [25]. Our previous studies show that in hESC-RPE cells, the spreading of mechanically induced $\mathrm{Ca}^{2+}$ waves strongly depends on cell culture time. In cells cultured for a longer period of time (28 days), the $\mathrm{Ca}^{2+}$ waves propagate to only few cells away from the stimulation site, similarly to the waves in rat RPE. On the other hand, the cells cultured for a shorter period of time (9 days) respond with wide-spreading $\mathrm{Ca}^{2+}$ waves, similarly to ARPE-19 [22].

In the current study, we demonstrated that in hESC-RPEs wounded on day 28 of culture and then allowed to heal for 7 days, mechanical stimulation resulted in widespreading intercellular $\mathrm{Ca}^{2+}$ waves, when a cell inside the healed wound had been stimulated. Inside the healed wounds, the cells have less mature morphology compared to the non-wounded surroundings, and indeed, such a strong response to mechanical stimulation is typical for immature hESC-RPEs.

On the other hand, control non-wounded areas exhibited more mature morphology, and the wave spreading was restricted to only few cells that is typical for more mature hESC-RPE cells, as we have shown in our previous study [22]. In contrast, the cells wounded on day 9 of culture and then allowed to heal for 7 days, did not show significant differences in the mechanically stimulated $\mathrm{Ca}^{2+}$ wave spreading in the healed areas and in control. The cells within the healed areas had similar morphology as the surrounding cells, and the $\mathrm{Ca}^{2+}$ wave spreading pattern corresponded to immature hESC-RPE cells. In addition, when cells were wounded on day 9 of culture and then healed for 7 days, the cells inside the healed area did not show significant 
difference in the percentage of cells with spontaneous $\left[\mathrm{Ca}^{2+}\right]_{i}$ activity compared to the surroundings. Thus, we can speculate that if there is no big difference in maturation status of the cells within the wound and in the surroundings, the cells can adapt to share similar $\mathrm{Ca}^{2+}$ dynamics behavior.

\section{Conclusions}

We have shown here that the effect of wounding on $\mathrm{Ca}^{2+}$ dynamics of hESC-RPE monolayers depends on cell culture time: 9-day-cultured freshly wounded cells have elevated amount of cells with spontaneous $\left[\mathrm{Ca}^{2+}\right]_{\mathrm{i}}$ increases in vicinity to the wound compared to control, whereas 28-day-cultured freshly wounded cells had similar $\mathrm{Ca}^{2+}$ dynamics around the wound edge as in other areas. Most importantly, we have shown that 28-day-cultured, wounded and thereafter 7-day-healed areas resemble the behavior of 9-day-cultured cells both in $\mathrm{Ca}^{2+}$ dynamics and cell morphology. In addition, we have demonstrated that cells cultured for a shorter period of time heal faster than cells cultured for a longer period of time. This acquired knowledge about $\mathrm{Ca}^{2+}$ dynamics in hESC-RPE cells is important for understanding the fundamental mechanisms of RPE wound healing that can lead to new insights in AMD pathological process and therapy.

\section{Additional files}

Additional file 1: Fig S1. Confocal images of non-wounded (A) and wounded (B) Regea08/017 hESC-RPE cultures in which COLI is shown in red and nuclei in blue. As seen from the ortho-sections on the right and above, the COLI is concentrated close to the substrata. This is indicated also with white arrows. The background labeling, which would be visible is other areas of the cell, is very low. Scale bars are $10 \mu \mathrm{m}$.

Additional file 2: Video S1. Calcium wave in hESC-RPE monolayer $(9 d+7 d)$ followed for $300 \mathrm{~s}$ after mechanical stimulation. The video corresponds Fig. 7A, B. Prior the stimulation hESC-RPEs $(9 d+7 d)$ were loaded with

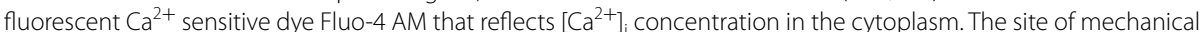
stimulation is marked with white an arrow. Mechanical stimulation of a single cell in a hESC-RPE monolayer resulted in a $\left[\mathrm{Ca}^{2+}\right]_{i}$ increase, seen as an increase in fluorescent signal, in the stimulated cell that propagates in a wave-like manner to neighbouring cells.

Additional file 3: Video S2. The video corresponds Fig. 7C, D. Calcium wave in hESC-RPE monolayer (28d + 7d) followed for $300 \mathrm{~s}$ after mechanical stimulation. Prior the stimulation hESC-RPEs were loaded with fluorescent $\mathrm{Ca}^{2+}$ sensitive dye Fluo-4 AM that reflects $\left[\mathrm{Ca}^{2+}\right]_{i}$ concentration in the cytoplasm. The site of mechanical stimulation is marked with white an arrow. Mechanical stimulation of a single cell in a hESC-RPE monolayer resulted in a $\left[\mathrm{Ca}^{2+}\right]_{i}$ increase, seen as an increase in fluorescent signal, in the stimulated cell that propagates in a wave-like manner to neighbouring cells.

\section{Abbreviations}

RPE: retinal pigment epithelium; hESCs: human embryonic stem cells.

\section{Authors' contributions}

Conceived and designed the experiments: AAK, JHy, KJ-U. Performed the experiments: AAK, KJ-U. Analyzed and interpreted the data: AAK, AR-M, Aka, JHy, KJ-U, Contributed regents/materials/analysis tools: AAK, AR-M, Aka, JHy, KJ-U Drafted the manuscript: AAK, KKa, HSk, JHy, KJ-U. Participated in the critical revision of the manuscript and approval of the article: AAK, AR-M, KKa, Aka, HSk, JHy, KJ-U. Acquired the funding: AAK, KKa, HSk, JHy, KJ-U. All authors read and approved the final manuscript.

\section{Author details}

${ }^{1}$ Faculty of Biomedical Sciences and Engineering, BioMediTech, Tampere University of Technology, Arvo Ylpön Katu 34, Tampere, Finland. ${ }^{2}$ Faculty of Medical and Life Sciences, BioMediTech, University of Tampere, Arvo Ylpön Katu 34 Tampere, Finland. ${ }^{3}$ Department of Ophthalmology, Institute of Clinical Medicine, University of Eastern Finland, Kuopio, Finland. ${ }^{4}$ Department of Ophthalmology, Kuopio University Hospital, Kuopio, Finland.

\section{Acknowledgements}

Outi Melin, Hanna Pekkanen and Outi Heikkilä are thanked for excellent technical assistance.

\section{Competing interests}

The authors declare that they have no competing interests. 


\section{Availability of data and materials}

After publication on the https://figshare.com.

\section{Consent for publication}

All authors have approved the final version of the manuscript.

\section{Ethics approval and consent to participate}

University of Tampere has the approval of the National Authority for Medicolegal Affairs Finland (TEO) to study human embryos (Dnro 1426/32/300/05) and a supportive statement of the Ethical Committee of the Pirkanmaa Hospital District to derive, culture, and differentiate hESC lines from surplus human embryos (R05116). No new lines were derived for this study.

\section{Funding}

This work was supported by the Academy of Finland [Grant Numbers 296840 (KKa), 252225 (JHy), 218050 (HSk) and 137801 (KJ-U)], the Finnish Funding Agency for Technology and Innovation (JHy, HSk), Päivikki and Sakari Sohlberg foundation (HSk), The Finnish Eye Foundation (KKa), and Tampere University of Technology President's Doctoral Program (AAK). The funders had no role in study design, data collection and analysis, decision to publish, or preparation of the manuscript.

\section{Publisher's Note}

Springer Nature remains neutral with regard to jurisdictional claims in published maps and institutional affiliations.

Received: 31 January 2018 Accepted: 24 July 2018

Published online: 31 July 2018

\section{References}

1. Sparrow JR, Hicks D, Hamel CP. The retinal pigment epithelium in health and disease. Curr Mol Med. 2010;10(9):802-23.

2. Strauss O. The retinal pigment epithelium in visual function. Physiol Rev. 2005;85(3):845-81.

3. Binder S, Stanzel BV, Krebs I, Glittenberg C. Transplantation of the RPE in AMD. Progress Ret Eye Res. 2007;26(5):516-54.

4. Klettner A, Kauppinen A, Blasiak J, Roider J, Salminen A, Kaarniranta K. Cellular and molecular mechanisms of age-related macular degeneration: from impaired autophagy to neovascularization. Int J Biochem Cell Biol. 2013;45(7):1457-67

5. Lopez PF, Sippy BD, Lambert HM, Thach AB, Hinton DR. Transdifferentiated retinal pigment epithelial cells are immunoreactive for vascular endothelial growth factor in surgically excised age-related macular degeneration-related choroidal neovascular membranes. Invest Ophthalmol Vis Sci. 1996;37(5):855-68.

6. Oganesian A, Bueno E, Yan Q, Spee C, Black J, Rao NA, Lopez PF. Scanning and transmission electron microscopic findings during RPE wound healing in vivo. Int Ophthalmol. 1997;21(3):165-75.

7. Hergott GJ, Nagai H, Kalnins VI. Inhibition of retinal pigment epithelial cell migration and proliferation with monoclonal antibodies against the beta 1 integrin subunit during wound healing in organ culture. Invest Ophthalmol Vis Sci. 1993;34(9):2761-8

8. Tamiya S, Liu L, Kaplan HJ. Epithelial-mesenchymal transition and proliferation of retinal pigment epithelial cells initiated upon loss of cell-cell contact. Invest Ophthalmol Vis Sci. 2010;51(5):2755-63.

9. Miura Y, Yanagihara N, Imamura H, Kaida M, Moriwaki M, Shiraki K, Miki T. Hepatocyte growth factor stimulates proliferation and migration during wound healing of retinal pigment epithelial cells in vitro. Jpn J Ophthalmol. 2003;47(3):268-75.

10. Wang H, Ninomiya Y, Sugino IK, Zarbin MA. Retinal pigment epithelium wound healing in human Bruch's membrane explants. Invest Ophthalmol Vis Sci. 2003:44(5):2199-210.

11. Guo CM, Wang YS, Hu D, Han QH, Wang JB, Hou X, Hui YN. Modulation of migration and Ca2+ signaling in retinal pigment epithelium cells by recombinant human CTGF. Curr Eye Res. 2009;34(10):852-62.

12. Croze RH, Thi WJ, Clegg DO. ROCK inhibition promotes attachment, proliferation, and wound closure in human embryonic stem cell-derived retinal pigmented epithelium. TransI Vision Sci Technol. 2016;5(6):7.

13. Gallagher-Colombo S, Maminishkis A, Tate S, Grunwald GB, Philp NJ. Modulation of MCT3 expression during wound healing of the retinal pigment epithelium. Invest Ophthalmol Vis Sci. 2010;51(10):5343-50.

14. Miyagishima KJ, Wan Q, Corneo B, Sharma R, Lotfi MR, Boles NC, Hua F, Maminishkis A, Zhang C, Blenkinsop T, et al. In pursuit of authenticity: induced pluripotent stem cell-derived retinal pigment epithelium for clinical applications. Stem Cells Transl Med. 2016;5:1562-74.

15. Singh R, Phillips MJ, Kuai D, Meyer J, Martin JM, Smith MA, Perez ET, Shen W, Wallace KA, Capowski EE, et al. Functional analysis of serially expanded human iPS cell-derived RPE cultures. Invest Ophthalmol Vis Sci. 2013;54(10):6767-78.

16. Cordeiro $\mathrm{JV}$, Jacinto A. The role of transcription-independent damage signals in the initiation of epithelial wound healing. Nat Rev Mol Cell Biol. 2013;14(4):249-62.

17. Tran POT, Hinman LE, Unger GM, Sammak PJ. A wound-induced [Ca2+], increase and its transcriptional activation of immediate early genes is important in the regulation of motility. Exp Cell Res. 1999;246(2):319-26.

18. Woolley K, Martin P. Conserved mechanisms of repair: from damaged single cells to wounds in multicellular tissues. BioEssays. 2000;22(10):911-9.

19. Wimmers S, Karl MO, Strauss O. Ion channels in the RPE. Progress Retinal Eye Res. 2007;26(3):263-301. 
20. Pearson RA, Catsicas M, Becker DL, Bayley P, Luneborg NL, Mobbs P. Ca(2+) signalling and gap junction coupling within and between pigment epithelium and neural retina in the developing chick. Eur J Neurosci. 2004;19(9):2435-45.

21. Pearson RA, Dale N, Llaudet E, Mobbs P. ATP released via gap junction hemichannels from the pigment epithelium regulates neural retinal progenitor proliferation. Neuron. 2005;46(5):731-44.

22. Abu Khamidakh AE, Dos Santos FC, Skottman H, Juuti-Uusitalo K, Hyttinen J. Semi-automatic method for Ca2+ imaging data analysis of maturing human embryonic stem cells-derived retinal pigment epithelium. Ann Biomed Eng. 2016;44:11.

23. Stalmans P, Himpens B. Properties of intra- and intercellular $\mathrm{Ca}(2+)$-wave propagation elicited by mechanical stimulation in cultured RPE cells. Cell Calcium. 1999;25(6):391-9.

24. Himpens B, Stalmans P, Gomez P, Malfait M, Vereecke J. Intra- and intercellular Ca2+ signaling in retinal pigment epithelial cells during mechanical stimulation. FASEB J. 1999;13(Suppl):S63-8.

25. Abu Khamidakh AE, Juuti-Uusitalo K, Larsson K, Skottman H, Hyttinen J. Intercellular $\mathrm{Ca}(2+)$ wave propagation in human retinal pigment epithelium cells induced by mechanical stimulation. Exp Eye Res. 2013;108:129-39.

26. Skottman H. Derivation and characterization of three new human embryonic stem cell lines in Finland. In Vitro Cell Dev Biol Anim. 2010;46(3-4):206-9.

27. Sorkio A, Porter PJ, Juuti-Uusitalo K, Meenan BJ, Skottman H, Burke GA. Surface modified biodegradable electrospun membranes as a carrier for human embryonic stem cell-derived retinal pigment epithelial cells. Tissue Eng Part A. 2015;21(17-18):2301-14.

28. Vaajasaari H, Ilmarinen T, Juuti-Uusitalo K, Rajala K, Onnela N, Narkilahti S, Suuronen R, Hyttinen J, Uusitalo H, Skottman $\mathrm{H}$. Toward the defined and xeno-free differentiation of functional human pluripotent stem cell-derived retinal pigment epithelial cells. Mol Vision. 2011;17:558-75.

29. Kapyla E, Sorkio A, Teymouri S, Lahtonen K, Vuori L, Valden M, Skottman H, Kellomaki M, Juuti-Uusitalo K. Ormocomp-modified glass increases collagen binding and promotes the adherence and maturation of human embryonic stem cell-derived retinal pigment epithelial cells. Langmuir. 2014;30(48):14555-65.

30. Sorkio A, Hongisto H, Kaarniranta K, Uusitalo H, Juuti-Uusitalo K, Skottman H. Structure and barrier properties of human embryonic stem cell derived retinal pigment epithelial cells are affected by extracellular matrix protein coating. Tissue Eng A. 2014;20:622-34.

31. Schmittgen TD, Livak KJ. Analyzing real-time PCR data by the comparative $C(T)$ method. Nat Protoc. 2008;3(6):1101-8.

32. Schindelin J, Arganda-Carreras I, Frise E, Kaynig V, Longair M, Pietzsch T, Preibisch S, Rueden C, Saalfeld S, Schmid B, et al. Fiji: an open-source platform for biological-image analysis. Nat Methods. 2012;9(7):676-82.

33. Geiger B, Bershadsky A, Pankov R, Yamada KM. Transmembrane crosstalk between the extracellular matrix-cytoskeleton crosstalk. Nat Rev Mol Cell Biol. 2001;2(11):793-805.

34. Carr AJ, Smart MJ, Ramsden CM, Powner MB, da Cruz L, Coffey PJ. Development of human embryonic stem cell therapies for age-related macular degeneration. Trends Neurosci. 2013;36(7):385-95.

35. Schwartz SD, Regillo CD, Lam BL, Eliott D, Rosenfeld PJ, Gregori NZ, Hubschman JP, Davis JL, Heilwell G, Spirn M, et al. Human embryonic stem cell-derived retinal pigment epithelium in patients with age-related macular degeneration and Stargardt's macular dystrophy: follow-up of two open-label phase 1/2 studies. Lancet. 2015;385(9967):509-16

36. da Cruz L, Fynes K, Georgiadis O, Kerby J, Luo YH, Ahmado A, Vernon A, Daniels JT, Nommiste B, Hasan SM, et al. Phase 1 clinical study of an embryonic stem cell-derived retinal pigment epithelium patch in age-related macular degeneration. Nat Biotechnol. 2018;36(4):328-37.

37. Schwartz SD, Hubschman JP, Heilwell G, Franco-Cardenas V, Pan CK, Ostrick RM, Mickunas E, Gay R, Klimanskaya I, Lanza R. Embryonic stem cell trials for macular degeneration: a preliminary report. Lancet. 2012;379:713-20.

38. Matsubayashi Y, Ebisuya M, Honjoh S, Nishida E. ERK activation propagates in epithelial cell sheets and regulates their migration during wound healing. Curr Biol. 2004;14(8):731-5.

39. Farooqui R, Fenteany G. Multiple rows of cells behind an epithelial wound edge extend cryptic lamellipodia to collectively drive cell-sheet movement. J Cell Sci. 2005:118(Pt 1):51-63.

40. Jacinto A, Martinez-Arias A, Martin P. Mechanisms of epithelial fusion and repair. Nat Cell Biol. 2001;3(5):E117-23.

41. Tran POT, Tran QHP, Hinman LE, Sammak PJ. Co-ordination between localized wound-induced Ca2+ signals and pre-wound serum signals is required for proliferation after mechanical injury. Cell Proliferat. 1998;31(3-4):155-70.

42. Shabir S, Southgate J. Calcium signalling in wound-responsive normal human urothelial cell monolayers. Cell Calcium. 2008:44(5):453-64.

43. Berra-Romani R, Raqeeb A, Torres-Jacome J, Guzman-Silva A, Guerra G, Tanzi F, Moccia F. The mechanism of injury-induced intracellular calcium concentration oscillations in the endothelium of excised rat aorta. J Vasc Res. 2012:49(1):65-76

44. Yin J, Xu K, Zhang J, Kumar A, Yu FS. Wound-induced ATP release and EGF receptor activation in epithelial cells. J Cell Sci. 2007;120(Pt 5):815-25 